\title{
Dynamic Analysis of Steel Eccentrically Braced Frames with Shear Link
}

\author{
Alireza Bahrami ${ }^{1,2 *}$, Mahmood Heidari \\ ${ }^{1}$ Department of Building Engineering, Energy Systems, and Sustainability Science, \\ Faculty of Engineering and Sustainable Development, University of Gävle, 80176 Gävle, Sweden. \\ ${ }^{2}$ Department of Civil Engineering, Abadan Branch, Islamic Azad University, Abadan, Iran. \\ Alireza Bahrami (corresponding author) ORCID: 0000-0002-9431-7820
}

ORCID: 0000-0003-0951-7260 (Mahmood Heidari)

\begin{abstract}
This paper offers the dynamic analysis of steel eccentrically braced frames (EBFs) with shear link under earthquake loads. The analysis was carried out using the finite element software ABAQUS. The verification of the EBF modelling was established by the comparison of the modelling result with that of the experimental test. Then, an EBF was designed with a shear link. Three different severe earthquake records of Tabas, Northridge, and Chi-Chi were selected for the analyses. Since the modelling accuracy was revealed, the method was utilised for modelling the developed EBF. The EBF was then analysed under the mentioned records. From the obtained results, the lateral displacements and energy dissipations of the frame and also shear link rotations were investigated. With regard to all the effects of the records as the lateral displacement and base shear of the frame and also the shear link rotation, it was found that the hierarchy of the records from their effects viewpoint on the EBF has been the Tabas, Chi-Chi, and Northridge earthquakes. In addition, the hierarchy of the energy dissipations of the records by the EBF has been the Tabas, ChiChi, and Northridge earthquakes, as well. Therefore, the developed EBF demonstrated a good performance in the energy dissipation of the earthquake records.
\end{abstract}

Keywords: Eccentrically Braced Frame, Dynamic Analysis, Earthquake Loading, Steel, Lateral Displacement, Base Shear, Energy Dissipation.

\section{INTRODUCTION}

Limiting the lateral displacement of structures which is usually resulted from the horizontal loads applied to them, particularly earthquakes, is of high importance that has greatly attracted the attention of researchers and engineers during the recent decades. Steel structures subjected to severe earthquakes have better performance than structures made of other materials such as concrete and masonry, which is due to the high strength, large ductility and high stiffness of the steel, and their more predictable failure modes than other above-mentioned materials. It is also more possible to replace and repair damaged components in the steel structures. On the other hand, the demolition of buildings and their structural components in an earthquake results in the waste of time, cost, and service, therefore, less damage of the steel structures in earthquakes which often depends on the ability of the energy dissipation of the braces reduces the damages and increases their use. This is because as the energy dissipation capacity enhances, the safety of the structures also improves. The ease of the application and effective performance of braces, especially in steel structures, have made them a suitable method of resisting lateral forces. Braces, as a passive control system, can play an effective role in creating structural resistance to lateral forces such as earthquakes.

The EBF is an earthquake resistant system in steel structures. The system is capable of having a good stiffness in its linear area against small earthquakes as well as having the ductility and ability to dissipate energy in its nonlinear area against large earthquakes. Some of the factors that justify the use of the EBFs include: reducing the lateral displacement compared with moment-resisting frames, the maximum height of tall buildings using the EBFs in areas with large earthquakes is less restrictive than those utilising concentrically braced frames (CBFs), reducing the force-displacement effect compared with moment-resisting frames, and ability to have wider spaces for openings compared with the CBFs. The performance of the EBFs in their linear and nonlinear areas is dependent on the length of the link. Under a severe earthquake, a plastic hinge is formed in the frame system which indicates having moment or shear link. The link length is one of the important parameters in the design of the EBFs. Short links fail in shear, while long links have flexural failure. The better performance of short links than long links has been demonstrated through numerous studies. The shear yield mechanism of short links is better than the flexural yield mechanism of long links because the shear force is constant throughout the short links and the non-elastic shear strains are uniformly distributed along the links which make creation of large non-elastic rotations of the links possible without creating a lot of local strains. In order to have the shear failure prior to flexural failure, the link length is limited to equation (1) in which the link is called a shear link, however, if the link length fulfils equation (2) it is a moment link:

$$
\begin{aligned}
& e<\frac{1.6 M_{p}}{V_{p}} \\
& e>\frac{2.6 M_{p}}{V_{p}}
\end{aligned}
$$

where $e, M_{p}$ and $V_{p}$ are the link length, plastic moment capacity, and plastic shear capacity of the steel section, respectively. 
Furthermore, if the link length falls between the ranges of the above equations, it will have a simultaneous flexural-shear failure. Thus, it is concluded that short links having a low $e / L$ ( $L$ as width, the frame span length,) ratio have high stiffness and strength for the EBFs which can also withstand large plastic rotations compared with moment links.

Some studies have been carried out on the behaviour of the EBFs [1-12]. However, this paper examines EBFs with shear link subjected to three different severe and famous earthquake records of Tabas, Northridge, and Chi-Chi.

This paper dynamically analyses steel EBFs with shear link subjected to earthquake loads. The finite element software ABAQUS is employed for the analyses. The EBF modelling and the experimental test results are compared with each other which uncover the modelling accuracy. An EBF with a shear link is then designed. The developed EBF is analysed under the Tabas, Northridge, and Chi-Chi earthquake records. The lateral displacements and energy dissipations of the frame and also shear link rotations are evaluated under the pre-mentioned records.

\section{METHODOLOGY}

The methodology of the current research is presented in the following sections:

\subsection{EXPERIMENTAL TEST}

An experimental test conducted on a steel EBF having hollow rectangular (i.e., tubular) cross-section with a link has been modelled in this study in order to reveal the accuracy of the modelling. Fig. 1 shows the setup of the experimental test. The height and width $(L)$ of the specimen were $3150 \mathrm{~mm}$ and $3660 \mathrm{~mm}$, respectively. In the test, the column end support was pinned. The horizontal force was applied to a loading beam using a hydraulic actuator. The loading beam distributed the load to clevises equally at the top of each column. The link details are provided in Fig. 2. The steel of the link was A572 Gr. 50 with a nominal yield strength of $345 \mathrm{MPa}$. HSS $178 \times 178 \times 12.7$ (US-7 $\times 7 \times 1 / 2$ ) and W $310 \times 143$ (US-12 $\times 96$ ) were used for braces and columns, respectively. The beam-to-column, brace-to-column, and brace-to-beam connections were designed as moment resisting. The loading protocol was applied based on the guidelines in ATC-24 [14].

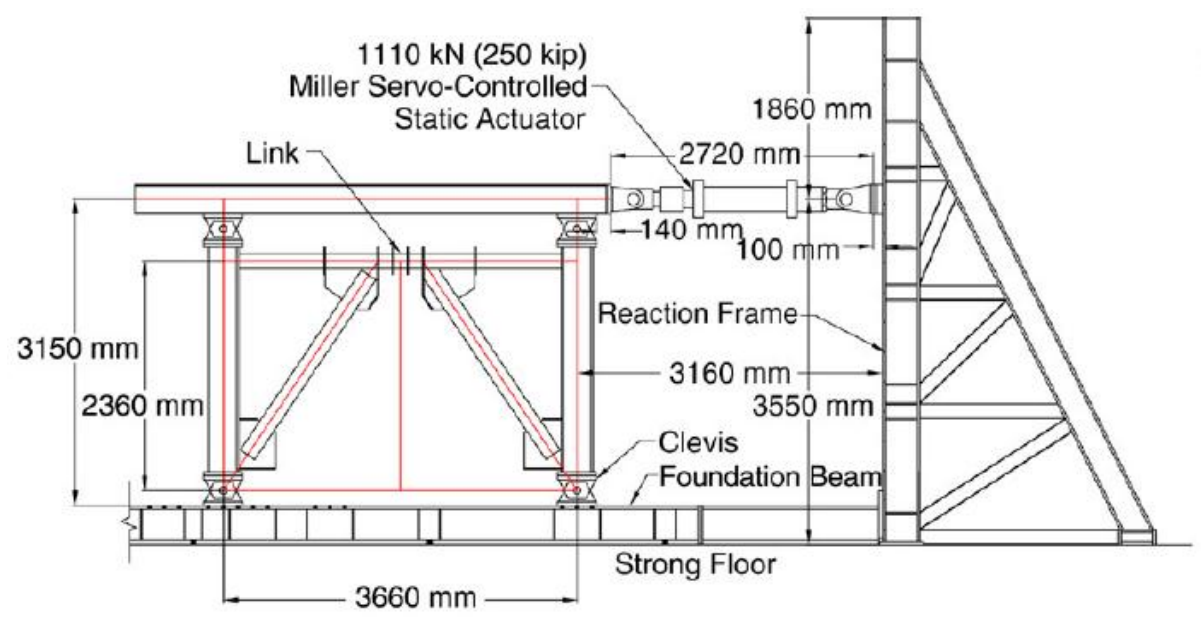

Fig 1. Setup of experimental test [13]

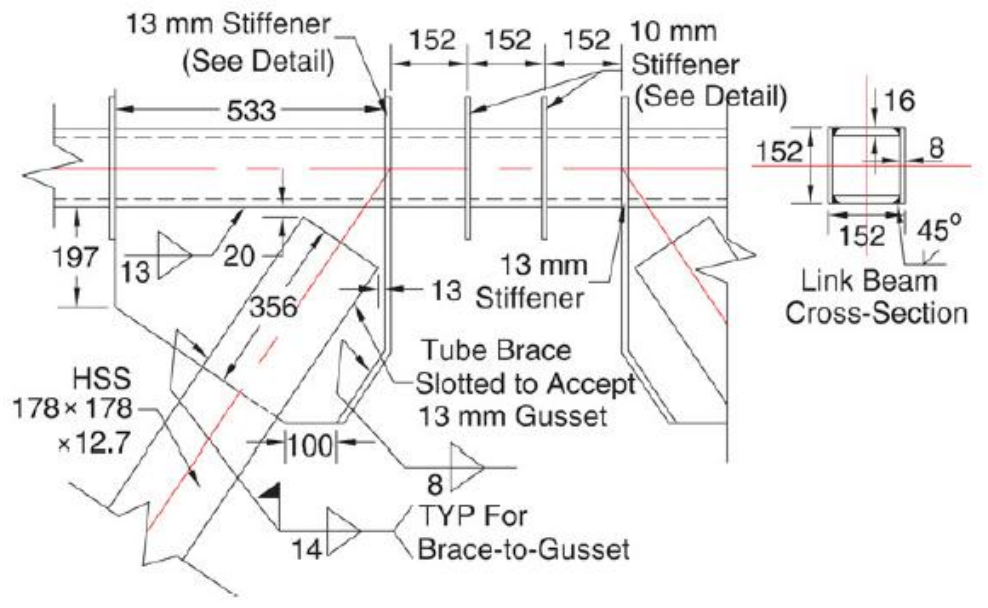

Fig 2. Link details [13] 


\subsection{MODELLING}

All the mentioned characteristics in the experimental test have also been applied in the modelling. The 4-node shell element S4R has been used to model the specimen members in the software. Modelling of the material has carefully been done as its essential part [15-18]. The steel has been simulated using a bilinear model also having kinematic hardening behaviour to consider progressive hardening and softening effects $[19,20]$. The loading and boundary conditions have been employed in the modelling as in the test. A detailed convergence study has been carried out in order to find the suitable mesh size for the model. Finally, the mesh size of $50 \mathrm{~mm}$ which could lead to accurate results has been selected for the modelling. Fig. 3 presents the modelled EBF.

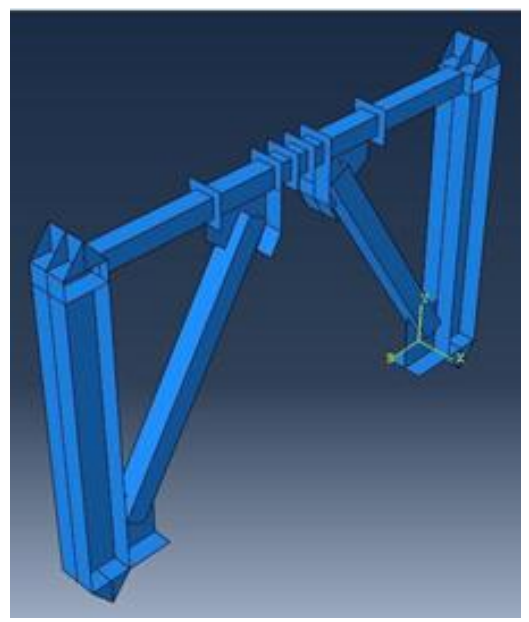

Fig 3. Modelled EBF

The obtained result from the modelling is depicted in the form of link shear-link rotation diagram. Fig. 4 illustrates the comparison of the modelling result (numerical) of this study with the experimental and finite element results. According to the figure, the modelling result correlates well with the experimental result which demonstrates the modelling accuracy. As a consequence, this modelling method is used for the analysis of the developed EBF.

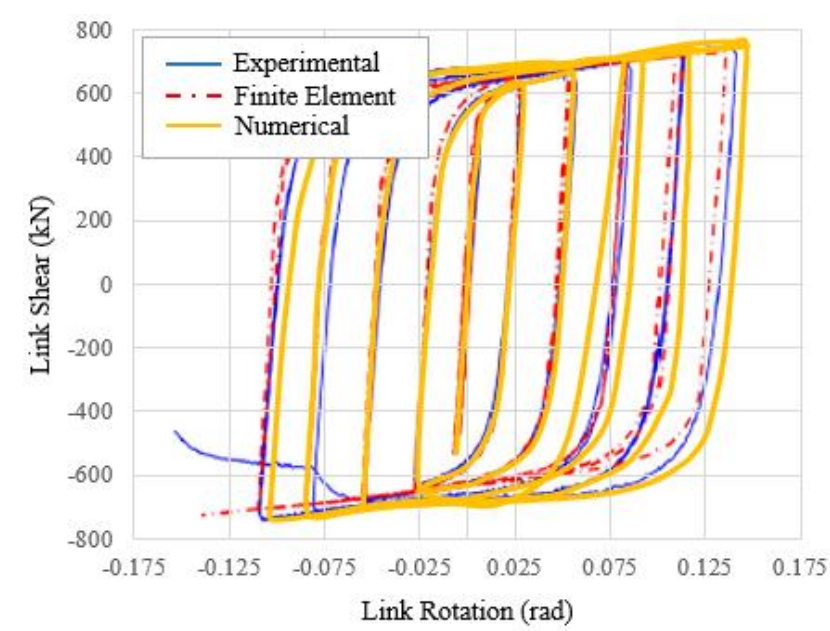

Fig 4. Comparison of modelling result (numerical) with experimental and finite element results

\subsection{DESIGN OF EBF WITH SHEAR LINK}

In order to assess the performance of the EBF under the earthquake loading, the verified EBF in the previous section has been designed with the shear behaviour of the link. Based on the design, the link length $500 \mathrm{~mm}$ and the stiffeners dimensions $180 \times 45 \times 8 \mathrm{~mm}$ with the spacing of $125 \mathrm{~mm}$ have been obtained. Thus, the mentioned features have been considered for the link of the EBF. Then, further analyses have been done on the EBF under earthquake loads.

\subsection{SELECTION OF EARTHQUAKE RECORDS}

Three different far-fault and near-fault accelerograms have been selected for the analyses of the EBF. Table 1 summarises features of these accelerograms. In the table, $\mathrm{M}_{\mathrm{w}}, \mathrm{PGA}, \mathrm{PGV}$, and PGD are respectively as the magnitude of the earthquake, the peak ground acceleration, the peak ground velocity, and the peak ground displacement.

Table 1. Features of studied records [21]

\begin{tabular}{|c|c|c|c|c|c|}
\hline Earthquake & $\begin{array}{c}\text { Site } \\
\text { Conditions }\end{array}$ & $\begin{array}{c}\mathrm{M}_{\mathrm{w}} \\
(\text { Richter } \\
\text { Scale })\end{array}$ & $\begin{array}{c}\text { PGA } \\
(\mathrm{g})\end{array}$ & $\begin{array}{c}\text { PGV } \\
(\mathrm{cm} / \mathrm{s})\end{array}$ & PGD (cm) \\
\hline $\begin{array}{c}\text { Northridge } \\
17 / 01 / 1994\end{array}$ & Soil & 6.70 & 0.349 & 32.25 & 9.30 \\
\hline $\begin{array}{c}\text { Chi-Chi } \\
20 / 09 / 1999\end{array}$ & Soil & 7.70 & 0.89 & 98 & 15.85 \\
\hline $\begin{array}{c}\text { Tabas } \\
16 / 09 / 1978\end{array}$ & Soil & 7.40 & 0.928 & 111.35 & 91.10 \\
\hline
\end{tabular}

\section{RESULTS AND DISCUSSIONS}

The geometry, material properties, and modelling features of the simulated EBF in this section are the same as those of the verified $\mathrm{EBF}$ in section 2.2, however, the shear link specifications are those designed in section 2.3. The pinned supports have been used for the frame. The earthquake records of Northridge, Chi-Chi, and Tabas (Table 1) have been applied to the frame. The dynamic time-history analysis has been employed in ABAQUS. The modelled EBF is presented in Fig. 5.

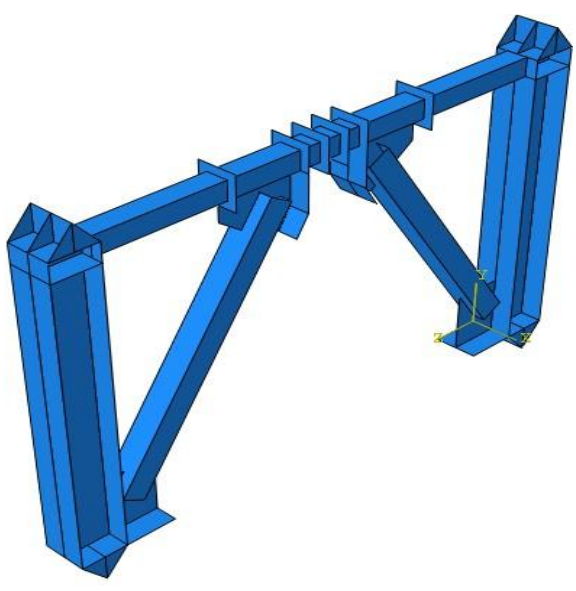

Fig 5. Modelled EBF with shear link under earthquake loads 
The obtained results are indicated and discussed below:

\subsection{COMPARISON OF LATERAL DISPLACEMENTS OF EBF WITH SHEAR LINK}

The diagrams of the obtained lateral displacements from the analyses of the EBF subjected to the different earthquake records are shown in Figs. 6-8. The maximum lateral displacements of the EBF under the earthquakes of Tabas, ChiChi, and Northridge are respectively as $3.7,2.15$, and $1.89 \mathrm{~cm}$, which have a direct relationship with the peak ground accelerations of the earthquakes (Fig. 9). Accordingly, the lateral displacement of the frame under the Tabas record is $72.1 \%$ and $95.8 \%$ larger than the lateral displacements of the frame subjected to the Chi-Chi and Northridge records, respectively. Also, the EBF has become unstable under the earthquake records of Tabas, Chi-Chi, and Northridge at the times of 10.9, 7.5, and 6.3 seconds that can be observed as an instantaneous displacement jump in the diagrams (Figs. 6-8).

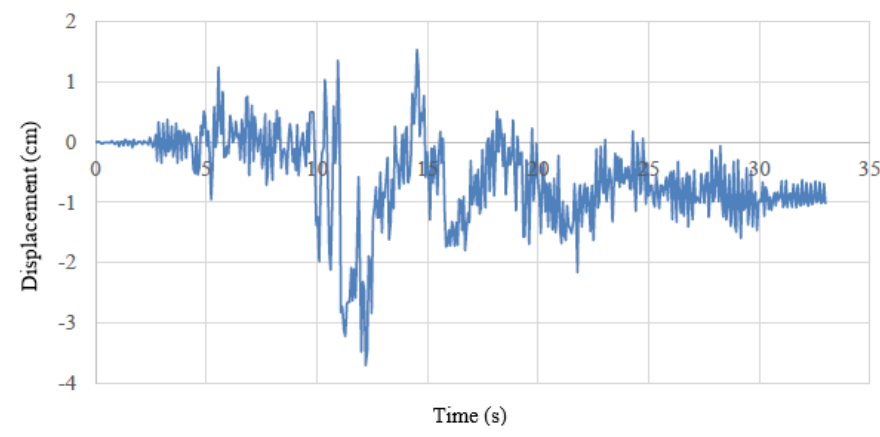

Fig 6. Lateral displacement of EBF with shear link under Tabas earthquake

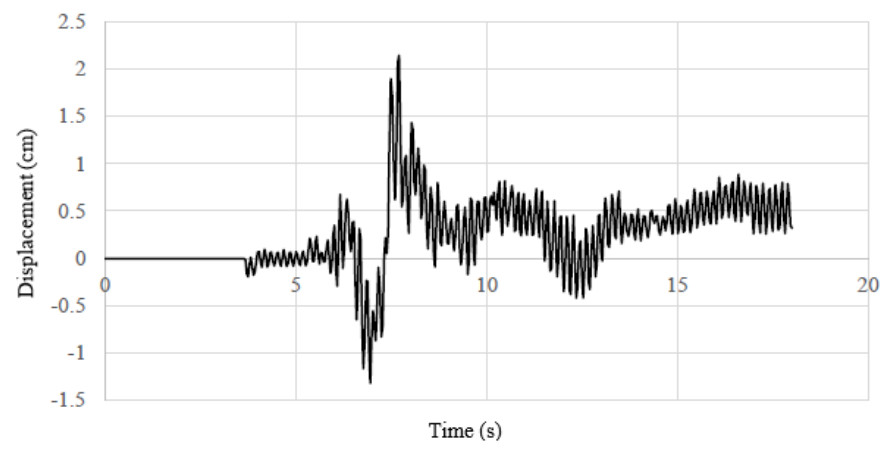

Fig 7. Lateral displacement of EBF with shear link under Chi-Chi earthquake

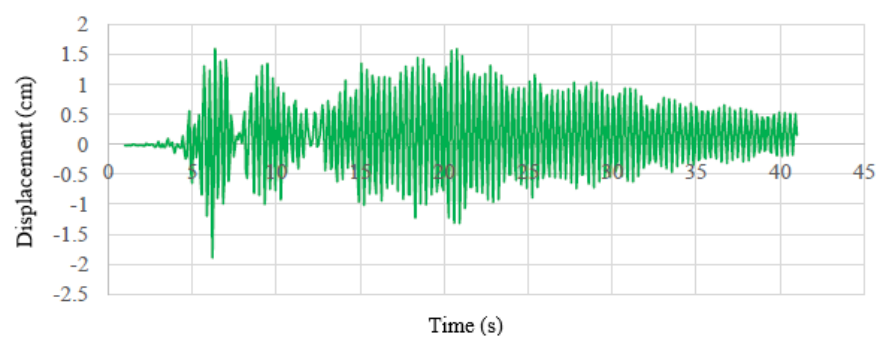

Fig 8. Lateral displacement of EBF with shear link under Northridge earthquake

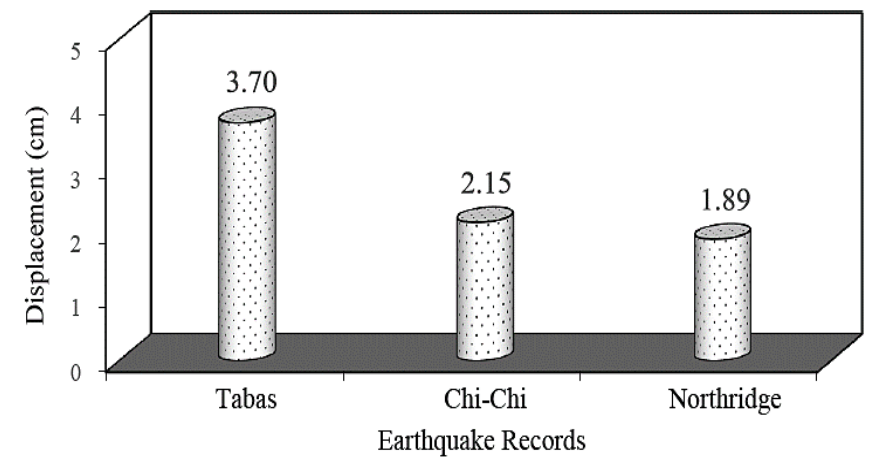

Fig 9. Comparison of lateral displacements of EBF with shear link under different earthquakes

\subsection{COMPARISON OF BASE SHEARS OF EBF WITH SHEAR LINK}

Figs. 10-12 illustrate the diagrams of the achieved base shears of the EBF under the earthquake records. Assessing the diagrams of the base shears indicates that the maximum base shear belongs to the frame subjected to the Tabas earthquake record as $6950 \mathrm{kN}$. Also, the base shears of the frame under the earthquakes of Chi-Chi and Northridge are $6460 \mathrm{kN}$ and $3660 \mathrm{kN}$, respectively, as displayed in Fig. 13. The base shear of the frame under the effect of the Tabas record is $7.6 \%$ larger than that subjected to the Chi-Chi record (Fig. 13), however, the displacement of the former is $72.1 \%$ greater than that of the latter (Fig. 9). The reason for this point can be because the difference in the response spectrum of the records in the constant acceleration region is slight, therefore, the force that is proportional to the acceleration will also have an inconsiderable difference, however, the difference of these two records is greater in the constant displacement area of the response spectrum, thus, the frame displacements will have larger difference. Meanwhile, the base shear of the frame under the Tabas record is $89.9 \%$ greater than that subjected to the Northridge record, whilst, the frame displacement is $95.8 \%$ larger. Moreover, the base shear of the frame subjected the Chi-Chi record is $76.5 \%$ greater than that under the Northridge record, however, the frame has $13.8 \%$ larger displacement.

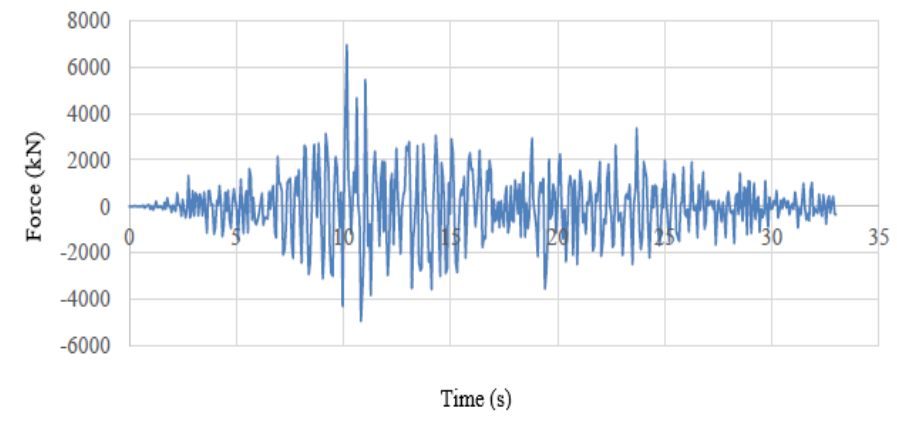

Fig 10. Base shear of EBF with shear link under Tabas earthquake 


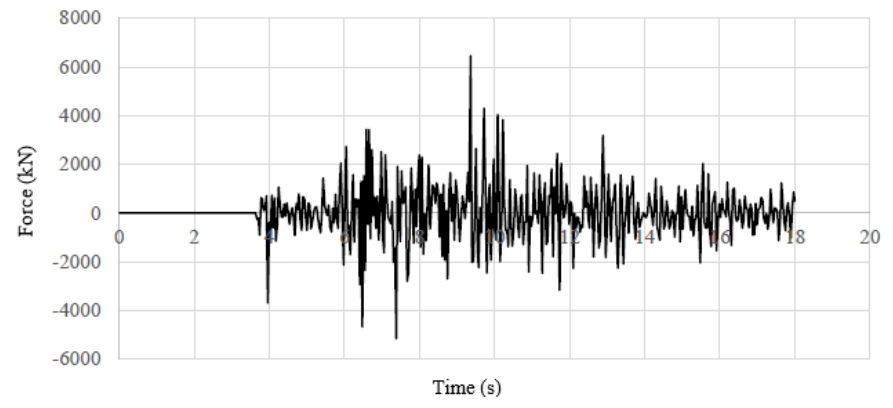

Fig 11. Base shear of EBF with shear link under Chi-Chi earthquake

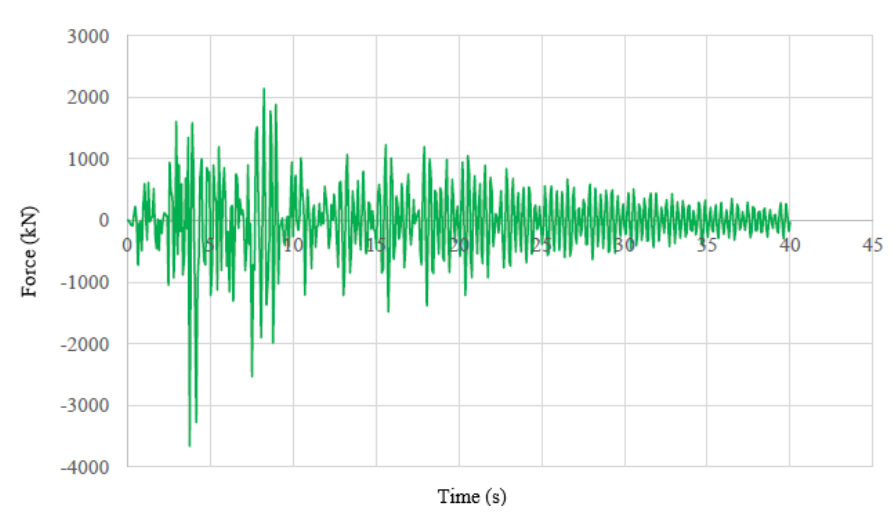

Fig 12. Base shear of EBF with shear link under Northridge earthquake

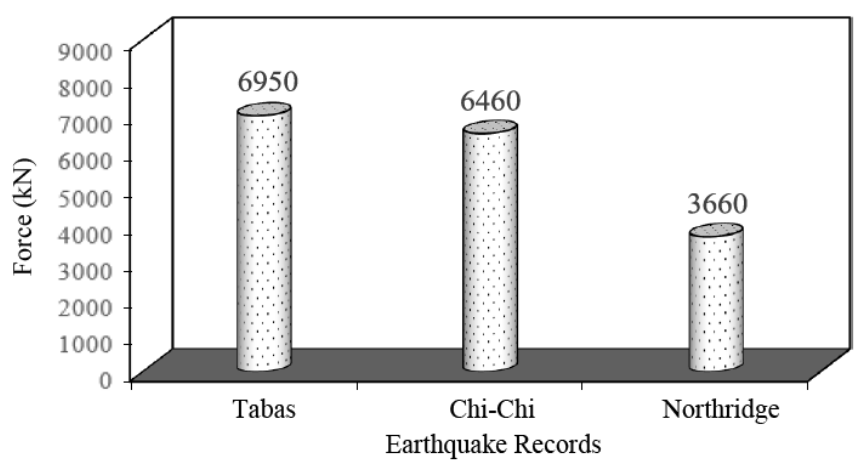

Fig 13. Comparison of base shears of EBF with shear link under different earthquakes

\subsection{COMPARISON OF ENERGY DISSIPATIONS OF EBF WITH SHEAR LINK}

The resulted energy dissipation diagrams of the frame subjected to the records are demonstrated in Figs. 14-16. In addition, Fig. 17 presents the comparison of the energy dissipations of the EBF under the different earthquakes. As it can be seen from Fig. 14, the maximum energy dissipation of the frame under the Tabas record is $112080 \mathrm{kN}-\mathrm{cm}$ which has been achieved during 33 seconds. During the first 5.5 seconds, the energy dissipation rate has been zero, then, it has been with a mild slope up to the second 10. At the second 10, the energy dissipation has reached $20000 \mathrm{kN}-\mathrm{cm}$, afterwards with a steep slope and quick energy dissipation during the next 10 seconds, it has reached $100000 \mathrm{kN}-\mathrm{cm}$. Finally during the last 13 seconds, its energy dissipation has been increased with a gentle slope. Furthermore, the large displacements of the frame for this record have begun at the second 10 and lasted up to the second 22 which caused $54 \%$ more damages than the Chi-Chi earthquake.

Fig. 15 indicates that the energy dissipation of the frame under the Chi-Chi earthquake record is $12693 \mathrm{kN}-\mathrm{cm}$ which has been accomplished within 18 seconds. During the first 6 seconds, the energy dissipation has been zero and the start of the energy dissipation has been at the second 6 with a steep slope which has then been increased up to the second 8 reaching the energy dissipation of $8000 \mathrm{kN}-\mathrm{cm}$. During the seconds 8 to 13 , the energy dissipation has been developed with a milder slope. The energy dissipation has been constant during the last 5 seconds of the process.

The energy dissipation of the frame subjected to the Northridge record is $3758 \mathrm{kN}-\mathrm{cm}$ during about 40 seconds (Fig. 16). The energy dissipation has been zero during the first 4 seconds and then with a jump the energy dissipation has reached $2300 \mathrm{kN}-\mathrm{cm}$ at the second 6 . Also, from the seconds 6 to 8 , the energy dissipation rate has been constant and then the energy dissipation has been improved with a jump, afterwards it has been enhanced with a low slope considering constant energy dissipation rate for the last 20 seconds.

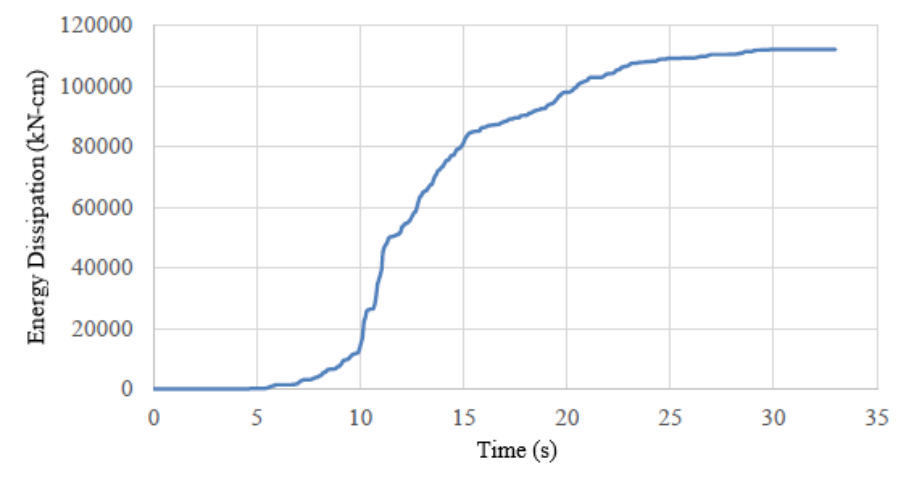

Fig 14. Energy dissipation of EBF with shear link under Tabas earthquake

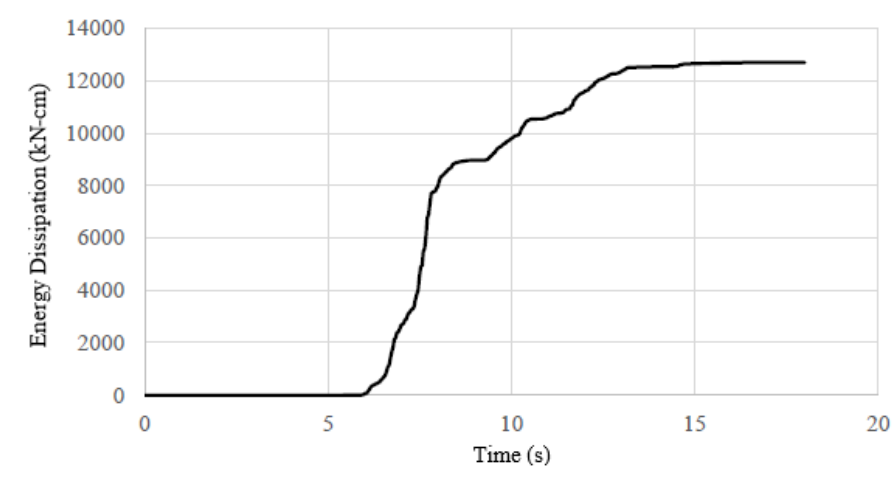

Fig 15. Energy dissipation of EBF with shear link under Chi-Chi earthquake 


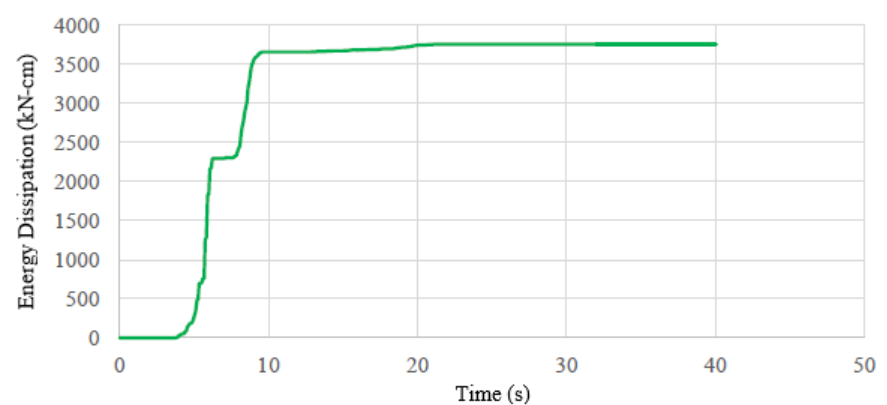

Fig 16. Energy dissipation of EBF with shear link under Northridge earthquake

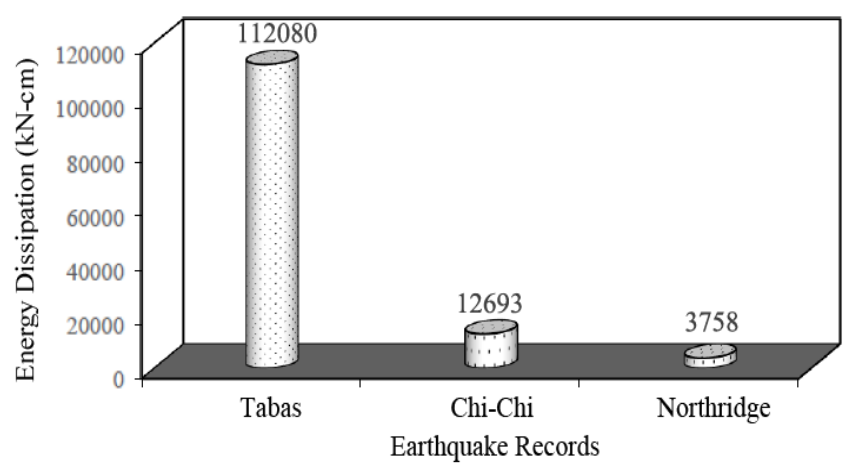

Fig 17. Comparison of energy dissipations of EBF with shear link under different earthquakes

\subsection{COMPARISON OF SHEAR LINK ROTATIONS}

The rotations of the shear link of the EBF under the different earthquakes have been compared in Fig. 18. The rotation of the shear link has been obtained from equation (3):

$$
\gamma=\frac{L}{e} \theta=\frac{L}{e} \times \frac{\Delta}{h}
$$

where $L, e, \Delta$, and $h$ are respectively as the width (the frame span length), link length, frame lateral displacement, and frame height.

The figure demonstrates that the rotation of the link under the Tabas earthquake is larger than those under the Chi-Chi and Northridge earthquakes, because the link rotation is directly related to the lateral displacement of the frame (equation (3)) and as it was mentioned in section 3.1, the lateral displacement of the frame subjected to the Tabas earthquake is greater than those of the frame under the Chi-Chi and Northridge earthquakes which leads to its larger rotation.

\section{CONCLUSIONS}

The dynamic analysis of the EBFs with shear link under the earthquake loads has been presented in this paper. The modelling accuracy was conducted by the comparison of the modelling result with the experimental test result. Then, the developed EBF was analysed under the effect of three various

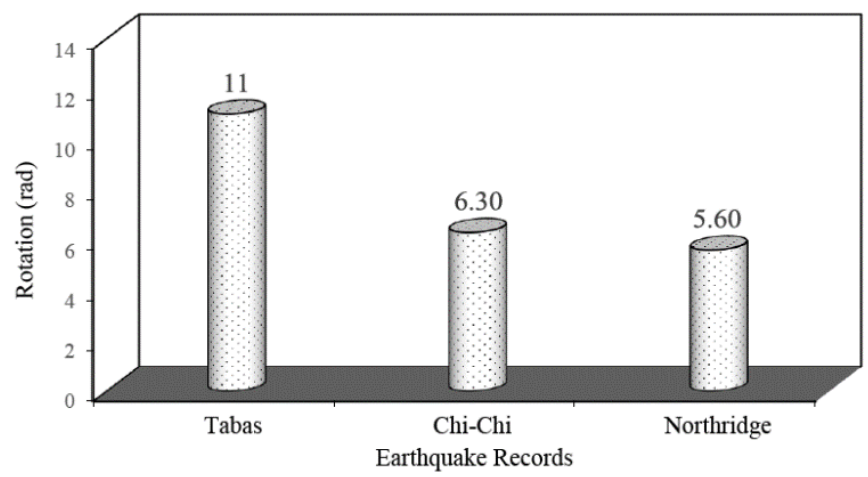

Fig 18. Comparison of rotations of shear link of EBF under different earthquakes

earthquake records of Tabas, Northridge, and Chi-Chi. The obtained lateral displacements and energy dissipations of the frame and also shear link rotations were compared under the effects of the above records. Considering all the effects of the records as the lateral displacement and base shear of the frame and also the shear link rotation, it was found that the Tabas, Chi-Chi, and Northridge earthquakes can be arranged in the order of the largest to smallest influencing records on the EBF in the current study. Moreover, the same order can be considered for the energy dissipations of the records by the EBF. Consequently, the developed EBF showed a good performance in the energy dissipation of the earthquakes.

\section{REFERENCES}

[1] C. W. Roeder and E. P. Popov, "Eccentrically braced steel frames for earthquakes", Journal of the Structural Division, vol. 104, no. 3, pp. 391-412, 1978.

[2] M. D. Engelhardt and E. P. Popov, "Experimental performance of long links in eccentrically braced frames", Journal of Structural Engineering, vol. 118, no. 11, pp. 3067-3088, 1992.

[3] A. Jain, S. Koboevic and R. Redwood, "Design and behaviour of eccentrically braced frames with flexural links", Advances in Steel Structures, Proceedings of International Conference on Advances in Steel Structures, Hong Kong, pp. 233-237, 1996.

[4] T. Okazaki, G. Arce, H-C Ryu and M. D. Engelhardt, "Experimental study of local buckling, overstrength, and fracture of links in eccentrically braced frames", Journal of Structural Engineering, vol. 131, no. 10, pp. 1526-1535, 2005.

[5] M. Bosco and P. P. Rossi, "Seismic behaviour of eccentrically braced frames", Engineering Structures, vol. 31, no. 3, pp. 664674, 2009.

[6] M. Ohsaki and T. Nakajima, "Optimization of link member of eccentrically braced frames for maximum energy dissipation", Journal of Constructional Steel Research, vol. 75, pp. 38-44, 2012.

[7] G. Yiğitsoy, C. Topkaya and T. Okazaki, "Stability of beams in steel eccentrically braced frames", Journal of Constructional Steel Research, vol. 96, pp. 14-25, 2014. 
[8] K. Young and H. Adeli, "Fundamental period of irregular eccentrically braced tall steel frame structures", Journal of Constructional Steel Research, vol. 120, pp. 199-205, 2016.

[9] M. Bosco, E. M. Marino and P. P. Rossi, "A design procedure for dual eccentrically braced-moment resisting frames in the framework of Eurocode 8", Engineering Structures, vol. 130, pp. 198-215, 2017.

[10] J. Ruiz-García, E. Bojorquez and E. Corona, "Seismic behavior of steel eccentrically braced frames under soft-soil seismic sequences", Soil Dynamics and Earthquake Engineering, vol. 115, pp. 119-128, 2018.

[11] E. Tapia-Hernández and S. García-Carrera, "Inelastic response of ductile eccentrically braced frames", Journal of Building Engineering, vol. 26, Article number 100903, 2019.

[12] Z. Yao, W. Wang, C. Fang and Z. Zhang, "An experimental study on eccentrically braced beam-through steel frames with replaceable shear links", Engineering Structures, vol. 206, Article number 110185, 2020.

[13] J. W. Berman and M. Bruneau, "Experimental and analytical investigation of tubular links for eccentrically braced frames", Engineering Structures, vol. 29, pp. 1929-1938, 2007.

[14] ATC. Guidelines for seismic testing of components of steel structures report-24. Applied Technology Council; 1992.

[15] A. Bahrami, W. H. Wan Badaruzzaman and S. A. Osman, "Structural behaviour of tapered concrete-filled steel composite
(TCFSC) columns subjected to eccentric loading", Computers and Concrete - An International Journal, vol. 9, no. 6, pp. 403426, 2012.

[16] A. Bahrami, W. H. Wan Badaruzzaman and S. A. Osman, "Investigation of concrete-filled steel composite (CFSC) stub columns with bar stiffeners", Journal of Civil Engineering and Management, vol. 19, no. 3, pp. 433-446, 2013.

[17] A. Bahrami, W. H. Wan Badaruzzaman and S. A. Osman, "Behaviour of stiffened concrete-filled steel composite (CFSC) stub columns", Latin American Journal of Solids and Structures, vol. 10, no. 2, pp. 409-439, 2013.

[18] A. Bahrami, W. H. Wan Badaruzzaman and S. A. Osman, "Performance of axially loaded tapered concrete-filled steel composite slender columns", Journal of Civil Engineering and Management, vol. 19, no. 5, pp. 705-717, 2013.

[19] A. Bahrami and S. Matinrad, "Response of steel beam-tocolumn bolted connections to blast loading", International Journal of Recent Technology and Engineering, vol. 8, no. 3, pp. 3639-3648, 2019.

[20] A. Bahrami and M. Yavari, "Performance of steel-concrete shear walls with two sided reinforced concrete", International Journal of Engineering and Technology Innovation, vol. 9, no. 3, pp. 228-239, 2019.

[21] http://ngawest2.berkeley.edu/. 